\title{
An Investigation into the Effects of Curriculum Enrichment on Creativity and Achievement Motivation of Gifted students in Public Schools
}

\author{
Elham Farsimadan
}

Department of Educational Sciences and Psychology, Payame Noor University (PNU), Tehran, Iran

Farzad Poorgholami

Department of Educational Sciences and Psychology, Payame Noor University (PNU), Tehran, Iran

Hajar Safari

Department of Educational Sciences and Psychology, Payame Noor University (PNU), Tehran, Iran

Ali Mohammad Ahmadi Gharacheh

PhD student in planning distance education. Department of Educational Sciences and Psychology Payame Noor University (PNU), Tehran, Iran

\section{Doi:10.5901/mjss.2015.v6n6s6p297}

\section{Abstract}

One of the main tasks of any educational system is to provide a proper field and opportunity for learning in order to flourish the various talents of students. In addition to such various needs of students, the needs arising from cultural and social requirements at national and regional levels and international requirements faced the educational systems with serious challenges. One way to solve such challenges is to design appropriate extracurricular activities to meet the educational needs of students in order to enhance their achievement motivation and creativity. This study was conducted in other to investigate the effect of curriculum enrichment on creativity and achievement motivation of gifted students in public schools of Farrashband, Fars, Iran. The present study is a descriptive study. The samples consists of all second and third grade students of public secondary schools in Farrashband, Fars, Iran the samples include 40 gifted students and 139 ordinary students they were selected as the study samples, using simple random sampling method. In this study, Torrance's Creativity Questionnaire (1965), Herman's Achievement Motivation Questionnaire (1970) as well as one researcher-made questionnaire was applied to assess curriculum enrichment. The data were analyzed using Pearson correlation coefficient, Independent t-test, and Manova. The obtained results revealed that there was a significant relationship between achievement motivation and educational attainment, and between creativity and educational attainment in students. Also, there was a significant relationship between curriculum enrichment and educational attainment of gifted students; however, there is no significant relationship was observed between curriculum enrichment and creativity which can be explained in this way that other factors such as personality and or familial traits may modify this relationship. In addition, there was no significant difference between talented and ordinary male and female students in terms of their achievement motivation and creativity. With regard to the findings of the current study, in order to improve the educational programs for students, it is suggested that special attention be given to the enrichment of educational facilities and also no difference be assigned to males and females in terms of creativity and achievement motivation in educational planning in the Ministry of Education.

Keywords: Curriculum Enrichment, Creativity, Achievement Motivation, Students

\section{Introduction}

The main objective of Extra-curricular activities is to strengthen the creative spirit in students Guildford believes that creativity is the divergent thinking. He argues that in divergent thinking, when faced with the problem, the mind swerved toward the indeterminate answer and different directions. While convergent thinking is used when there is a comprehensive solution for the problem, but when there are no solutions are offered, a range of solutions are offered, so divergent thinking is applied (Karimi 2006). One of the first incentives that is studied with creativity and as creativity motive is the need to progress or Achievement Motivation. We all know people who constantly progressing, succeed, 
invent and seemingly they do impossible tasks. Strengthen this incentive can improve the low motivation lives and defines the progress as a desire or interest to success generally or being successful in a particular field. Slavin believes that people with high levels of motivation are very diligent to solve problems and achieve success Even after they failed they do not stop it to achieve a breakthrough and they continue their efforts (Slavin, translated by Seyed Mohammadi. 2006). The Structure of achievement motivation in school defined as the behaviors which are related to learning and progress. Hausen thinks that academic achievement motivation is more exclude to the dimension that is called intrinsic motivation of students. Intrinsic motivation is a psychological state and comes when the man himself has enough sufficient and self-control (Omidvaar, Hedayat, Azim, 2013).

Corman defined Achievement Motivation as a wish to surpass in a particular behavior, especially a behavior that is changed to a criterion or criteria (Corman, 1997; translate by Shokrkon, 2007). In the same way Sternberg did the same research over 110 students. The topic of his research was "creativity education effect on students' performance". The effectiveness of training the students' creativity referred to their cognitive and personal characteristics (Pirkhaefi, 2009). Make et al examine the impact of exploration (educational) programs focused on elementary students in an investigation. The results show that active learning, curriculum chosen by the students, access to resources, exploration and selfassessment significantly increase students' creativity (Make, Sonmy, Momar, 2009). Torrance criticized the traditional education and emphasized the importance of changing the traditional development and conduct training programs toward a creative curriculum. These researchers believe that to achieve this we should enrich the learning environment and provide creative programs (Torrance, 1990).

Educational value of extra-curricular activities is not only less than formal activities, but in some cases even more than they are. For both teachers and students in extracurricular activities feel freer and therefore they are more willing to them and use these activities more (Zahiri, 2003). Perhaps the greatest way for gifted students across the world have been used, is the enrichment of the curriculums of the public schools. Rich curriculum means the addition of activities that develop intellectual skills or a special creativity of gifted students. This means that the current program will be more flexible and lesson plans based on the needs and demands of of students and their abilities (Naderi, Hossein Nejad, Zain Abadi, 2012). Renzulli and Rees present enrichment model based on this belief that the kids show talented behaviors in special fields and activities in order to show their higher creativity, commitment to duty and their above-average ability for doing these activities.

Enrichment programs for talented or gifted students should carry out based on their needs, interests, abilities, and creative power, and their educational degrees. Gifted students need an environment where educational facilities are in such a way that stimulates their Creativity. Interests, knowledge and abilities of gifted and talented students are very wide and they are in higher level in comparison with other students. Therefore, their training must be based on recognition of their capabilities, tastes, talents, and interests, intellectual, psychological, and emotional needs, which were very heterogeneous and advanced in such people (Renzully, Rice, 1997). In order to enrich the training programs we must provide an environment for students to apply their abilities. The implementation of this program seems to be very difficult, because class rules and programs and the time of these classes sometimes prevent the implementation. These rules, in many cases is not adapted with advanced abilities, curiosity, spirit of exploration, independence and autonomy of gifted student and usually prevents the mental development of these students. In this research we should create innovation in existing programs this enable us to recognize the most capable students and help them to raise their talents. In the training and educating of gifted students educational enrichment programs have full attention at the role of teacher and administrator and their effect on the characteristics of gifted students In addition to teaching styles and educational facilities and in this case the teachers' training has a special status. Basically, the training should be tailored to students' talents. As this training is richer students have more opportunities for growth and are ready for understanding that they need to it in the present and future. So the main questioning this research is that whether the enrichment program will cause the growth of creativity and motivation of students?

The second question is, now that the training conditions and facilities for Male and Female is almost the same between gifted and ordinary Male and Female students, is there any significant differences in terms of their Achievement Motivation and creativity?

\section{Methodology}

The samples consist of all students, gifted and ordinary, of second and third grade that is educating in secondary school in the school year 2012-1013 in Farrashband. Among all grades of secondary school 40 students were selected as a group of gifted students. Criteria for the selection of gifted students is in this way that each student in public schools should be among the three top students of his/her class in the three past years and also the teachers must confirm their 
abilities. And also 139 ordinary students were selected using simple random sampling method. The research instruments include:

\subsection{Herman's Achievement Motivation Questionnaire}

In the present study for assessing achievement motivation we use Hermans' achievement motivation test (Hermans, Tarlek, Miss., 1997). Based on empirical methods and theories about achievement motivation Hermans make a questionnaire contains 92 questions initially. But according to existing researches, 10 distinguishing features of those with high achievement motivation of people in comparison with those with low achievement motivation are used to make above mentioned questionnaire and limit the number of questions to 29 according to Development indexes (Akbari, 2007). This test is valid. The correlation coefficients for the questionnaire were reported, in a range of $57 / 0$ to $30 / 0$ (Raees Saadi, 2007). In this study, the reliability was $80 / 0$.

\subsection{Torrance's Creativity Questionnaire}

Torrance's Creativity questionnaire (Torrance, Goff, 1990) containing 60 questions and each question have three options that measures creativity. Options represent the creativity from low to high which include the scores 1,2 and 3 respectively. So the maximum $\mathrm{f}$ scores will be 180 and the minimum will be 60 . Various researchers used this scale in their study, and it confirmed the validity of this scale. In this study, by using Cronbach's alpha the reliability of this scale was reported 69 / 0 a that is satisfactory.

\subsection{Curriculum Enrichment}

We used the researcher-made questionnaire to check the quality of educational enrichment program the researcher made this questionnaire and implement it according to the purpose of his study. The questionnaire included 25 items on a Likert scale graded from strongly agree $=5$ degree to strongly disagree $=1$. In this study, Cronbach's alpha for the 25 item questionnaire of educational enrichment equals 84 / $0 \mathrm{a}$ that is satisfactory.

To check the validity we correlate each item with the total score so the measure of validity was obtained that was satisfactory.

\section{Findings}

The findings of this study shows that among gifted group(40 students) 22 students are female and 18 students are male among the ordinary group 79 students are female and 60 students are male. The average score of gifted students was 19.51 and the average score of ordinary students was 17.15. The literacy rate for gifted students' father and mother were respectively 55 and 27 percent higher than diploma. And for ordinary students these percentages were respectively 27 and 10.

Table 1. Correlation coefficient between creativity, Achievement Motivation, and academic achievement of ordinary and gifted students

\begin{tabular}{|c|c|c|c|}
\hline Variables & creativity & Achievement Motivation & academic achievement \\
\hline Creativity & 1 & - & - \\
\hline Achievement Motivation & ${ }^{\star} 0 / 43$ & 1 & - \\
\hline Academic Achievement & ${ }^{*} 0 / 24$ & *0/29 & 1 \\
\hline
\end{tabular}

As you can see in the above table there was a significant relationship between creativity and academic achievement. There was also a significant correlation between creativity and achievement motivation. 
Table 2. The correlation coefficient between educational enrichment program and creativity in gifted students

Variables
Academic achievement
Achievement Motivation

Sample Group
Achievement Motivation
Educational enrichment program
Creativity
Educational enrichment program

\begin{tabular}{|c|c|c|c|}
\hline Average & SD & $r$ & $p$ \\
\hline 107.94 & 9.64 & & \\
\hline 94.69 & 1.36 & 0.32 & 0.025 \\
\hline 114.80 & 10.05 & & \\
\hline 94.69 & 1.36 & 0.12 & 0.22 \\
\hline
\end{tabular}

As specified in the table above there was a significant relationship between the enrichment of the learning environment and achievement motivation $(r=32 / 0$ and $p=025 / 0)$. as mentioned in above table there wasn't any significant relationship between Educational enrichment program and creativity.

Table 3. The comparison between ordinary and gifted students in terms of Creativity, Achievement Motivation, and Academic achievement

\begin{tabular}{|c|c|c|c|c|c|}
\hline Variables & Sample Group & Average & SD & $r$ & $p$ \\
\hline \multirow{2}{*}{ Academic achievement } & Gifted students & 19.51 & 0.4 & \multirow{2}{*}{7.36} & \multirow{2}{*}{0.001} \\
\hline & Ordinary students & 17.15 & 1.84 & & \\
\hline \multirow{2}{*}{ Achievement Motivation } & Gifted students & 40 & 107.94 & \multirow{2}{*}{2.79} & \multirow{2}{*}{0.007} \\
\hline & Ordinary students & 138 & 102.81 & & \\
\hline \multirow{2}{*}{ Creativity } & Gifted students & 114.80 & 10.05 & \multirow{2}{*}{3.94} & \multirow{2}{*}{$<0.001$} \\
\hline & Ordinary students & 107.57 & 10.66 & & \\
\hline
\end{tabular}

As you can see there was a significant difference between gifted and ordinary students in terms of creativity $(t=3.94$ and $p<0.001$ ) So that the gifted students' average creativity is higher than the ordinary students' average creativity. And also there was a significant difference between gifted students and ordinary students in terms of achievement motivation ( $t$ $=2.79$ and $p=0.007$ ) so that the gifted students' average achievement motivation is higher than ordinary students.

There was a significant difference between gifted students and ordinary students in terms of academic achievement $(t=7.36$ and $p=0.001)$ in a way that the gifted students' average achievement motivation is higher than ordinary students.

Table 4. Comparison between male and female gifted students and ordinary students in terms of achievement motivation and Creativity.

\begin{tabular}{|c|c|c|c|c|c|c|}
\hline \multicolumn{2}{|c|}{ Variables } & Sample group & Average & SD & $\mathrm{F}$ & $p$ \\
\hline \multirow{4}{*}{ Creativity } & \multirow{2}{*}{ Gifted students } & Male & 113.50 & 10.22 & \multirow{4}{*}{0.7} & \multirow{4}{*}{0.79} \\
\hline & & Female & 116.28 & 10.8 & & \\
\hline & \multirow{2}{*}{ Ordinary students } & Male & 106.71 & 9.48 & & \\
\hline & & Female & 108.47 & 11.47 & & \\
\hline \multirow{4}{*}{ Achievement motivation } & \multirow{2}{*}{ Gifted students } & Male & 106.16 & 9.21 & \multirow{4}{*}{0.001} & \multirow{4}{*}{0.995} \\
\hline & & Female & 109.47 & 9.96 & & \\
\hline & \multirow{2}{*}{ Ordinary students } & Male & 100.93 & 11.30 & & \\
\hline & & Female & 104.26 & 11.72 & & \\
\hline
\end{tabular}

As specified in the table above there wasn't any specific difference between male and female gifted students and ordinary ones in term of achievement motivation ( $F=0.001$ and $p=0.995)$ It is also there was no significant difference among female and male gifted students and ordinary ones in term of creativity ( $F=0.7$ and $p=0.79)$.

\section{Results and Disscussion}

As we have seen, a significant relationship was found between motivation and academic achievement. This is consistent with Bagheri's findings (Bagheri, Namazian, Amiri, 2012) and Yousefi (Yousefi, 2008). One of the requirements of 
academic achievement is having achievement motivation. So focusing on students' psychological and motivational problems can be important and effective in their academic achievement. we can define the importance of motivation in learning in this way If the students are not interested in their lessons or if they were in a low level of motivation they won't pay attention to the teachers' explanations they Do not continue their assignments seriously and do not get much progress in their courses vice versa If the students are interested in their lessons or if they were in a high level of motivation they listen $t$ their teacher carefully and continue their assignment seriously they Looking for more information to collect and subsequently they get progressed. The data showed a significant correlation between creativity and achievement motivation and academic achievement. This finding is consistent with Postigo (Postigo, 2002), Fustigo (Fustigo, 2005), Slavin (Slavin, 2006) and Zahabioun and Ahmadi (Zahabioun, Ahmadi, 2009). So it can be said that people who have high achievement motivation and love to achieve their goals and plan to reach them by reaching their goals they are on the path of progress and these all can provide the basis for innovation. By the way a person show his/her creativity when he/she has a strong motivation in this field because without motivation if you have a creative potential this potential will not actualize. This relationship would be stated like this: the creativity can also cause academic Achievement. Creativity is the result of heredity and of environment (Afrooz, 2011). So creativity can gives incentives to people to work harder for their academic achievement it also enhances motivation and eventually it increases academic achievement.

The results showed that there was a significant relationship between the enrichment of the learning environment and achievement motivation of talented students. That are consistent with Adhami et al research results (Adhami, Javadi, Haghdoost, 2002), and (Zare, Davyjany, 2012). Zare Davyjany in his research found that familiarity with information technology has a great impact on students' progress. As it stands, both at home and at school facilities will increase students' progress and efficiency. However, according to Piaget facilities and technology should fit the child's development to have a positive impact otherwise if the facilities go beyond the level of child and student growth it would destroying his/her achievement motivation. Research has shown that learning contributes $70 \%$ of visual and $13 \%$ of auditory, while in the schools more attention and focus is on the sense of hearing. If the student use of audiovisual aids such as slide film, audio tapes, laboratory instruments and these aides are involved in, the student's learning will be more durable and more effective. One of the features of having facilities in schools is that we have stylish and fun classes Because if classes looks fun it can increase student's motivation to have better academic achievement(Adhami, Javadi, Haghdoost, 2002).

The results showed that there weren't any significant relationship between the enrichment of the learning environment and creativity in talented students. So these findings are consistent with the results of Nakhaei et al (Nakhaei, Joseph, 2011), (Rezaei Rad and Abazari, 2010), (Hosseini, Bahrami, 2002). Rezaei-Nejad and Abazari in their study found that knowledge of ICT is positively associated with creativity of the staffs of education and training office. So existence of facilities such as educational technology, computers, equipped laboratories, sympathetic teachers and developed schools and...Makes a lot of students open their ideas and to experiment and research in that field. Lots of creativities may just be as same as simple ideas, and students do not have the required situation for its development but if the fields and facilities were provided these ideas may come to actuality or the existence of facilities may directly leads to creativity. Existence of facilities may also cause the creativity in teachers and teachers can provide the necessary environment for creative students. As Torrance (Torrance, 1990) concluded that the teacher in the classroom is the decisive factor in increasing students' creativity Hosseini (Hosseini, Bahrami, 2002) showed that if appropriate training structure is provided to teachers their knowledge increased and their attitudes changed and They can use modern teaching skills and teach in a way that increase the students creativity.

These all finding are consistent with the finding of our research. Torrance (Torrance, 1990) criticized the traditional education and emphasizes on the importance of changing the traditional program and conducts the training toward creative programs. He believes that to achieve this we should enrich the learning environment and provide innovative programs so training the creative teachers, in order to train creative students is very important.

The absence of this relationship can be explained by other factors such as personality, family factors, genetic factors which modify the relationship between creativity and the enrichment program. Results showed there was a significant difference between gifted and ordinary students in terms of academic achievement and achievement motivation so that talented students' average of academic achievement is higher than ordinary students.

Yousefi (Yousefi, 2008) in a study called the relationship between academic motivation and academic achievement of students found that academic motivation have a direct relationship with clinical GPA that is accordant with the results of this study. Since gifted students due to internal motivation and external incentives are always encouraged. So it is clear that these students have a better grade point average than other students. The around people are in the role of external incentives who added incentive to students' progress to maintain his/her success and if they fall behind in school prepare 
the conditions for their prosperity by entering on time and doing some effective tasks .

When there are differences between gifted and ordinary students in terms of achievement motivation it means that talented students have higher achievement motivation and this motivation may be received from different incentives in their families. Those who use normal parenting styles usually encourage their children's progress and always encourage their children in front of others, by this the parents attract the attentions of others to their children and in the future whether at home or at school they help their children to be the best. So parents and teachers should encourage children for their progress so they strengthen them internally and provide them the way forward.

As Mac Land stated the motivation can be boosted by training and education, family and social environment play a major role in its development. According to her, achievement motivation is not a hereditary trait and students who had attended training courses to improve achievement motivation, work better than they did before and become more successful (the Corman, 1997 translated by Shokrkon 2007). A significant difference was found between gifted and ordinary students in terms of creativity. So the average creativity of talented students was higher than average creativity of the ordinary students. Since creativity and innovation requires high intelligence so it can be assumed that talented students through their high intelligence can be more creative and do their works more creative. However, some experts have also said that talented students are not necessarily creative (Masen, 2007).

But it can be argued that creativity should not necessarily lead to creation. Even having new ideas or solve problems in different ways counted as creativity that can provide creation fields. As shown in Table 4-16 there weren't any significant difference between Male and Female gifted students and ordinary ones in terms of creativity.

This is consistent with Ghorbanzadehs findings (Ghorbanzadeh, 2000) and (Manafi, 2003), they found no significant relationship between individual characteristics such as education level, gender and age of creativity. Also in these researches Osanlooet al (Osanloo, Asadi, Goudarzi, Kazemnejad, 2006), Khosravani and Gilani (Khosravani and Gilani, 2007), Noori (Noori, 2007), and Shaykh al-Islam, Razavieh (Shaykh al-Islam, Razavieh, 2002) there wasn't any significant difference between Male and Female students But this is not consistent with Tarang and Taghavi (Tarng and Taghavi, 2008) and Hosseinkhah and Vahedian (Hosseinkhah and Vahedian, 2011), which showed that there was no significant difference between Males and Females in terms of creativity.

Researches in the field of creativity and sex differences were not consistent with each other. the investigations shows that the Male students is better in creativity but the Female students are usually better in verbal creativity and have better scores in fluidity and imagination test but overall scores of Male students were better than Female ones.

As the results showed there was no significant difference between Male and Female gifted students and the ordinary ones in terms of achievement motivation. In the case of sex differences in academic performance in the past and today there are different views on this issue the first discussion is about the impact of gender and education, and the relationship between sex differences in educational and cognitive abilities. Prevailing thought in the 19th century and early 20th century showed less cognitive abilities of women than men, but the use of intelligence tests later showed that there was no difference between Males and Females. According to conducted researches there are no sex differences in general intelligence (Khosravi, 2003).

During the pre-school, Females scored higher on intelligence tests but in high school, Males scores higher in these tests because it may be because of more Males with low capacity drop the school. In discussing the academic achievement results indicate that Females have higher academic achievement than Males in elementary school and this is true even in math and science, in high school and pre-university there is a small difference and even the Females are better in the early years. Arnat also emphasized the difficulty of comparing the academic performance of Males and Females and limit the comparisons to specific aspects of the curriculum he believed that at all levels of development and learning is equal for Males and Females. However, in the last quarter of the twentieth century, we can distinguish three different periods in the academic achievement of Males and Females, in 70s that the Females had lower academic achievement, in the 80s that the level of academic achievement was equal in males and females, and in 90s which the females passed the man and had higher academic achievement level (Rastegar, 2010).

\section{Conclusion}

The results showed that there is a relationship between creativity, motivation and academic achievement. There is a significant relationship between Enrichment of educational facilities and academic achievement in gifted students, but there is no relationship between creativity and facilities. Also there is no significant difference between male and female ordinary and gifted students. One of the main limitations of this study was a self-administered questionnaire for collecting data. 


\section{Acknowledgment}

This article is taken from a thesis of training Management of Islamic Azad University of Bushehr. We want to thank and appreciate all those who helped us in conducting this research.

\section{References}

Adhami, Ashraf, Javadi, Yadollah, Haghdoost (2002).the relationship between educational facilities and human resources of basic sciences with academic achievement of students of medical sciences of Kerman .the sixth scientific magazine of Qazvin university .p. 56-63(2).

Slavin, Ray (2006).training psychology translated by: Yahya Seyed mohammadi. th edition .Dowran publication.

Osanlo.P, Asadi. H, Goodarzi. M, Kazem nejad. A (2006). Study the effects of personal characteristics of managers at P.E Organization and ministry of education, Researches and technology on creativity and confliction management. Harkat Quarterly, $30^{\text {th }}$ edition.

Afrooz.Gh (2011).An introduction to psychology and education and training of exceptional students. Tehran university publication.p.141.

Akbari.B (2007). The reliability and validity of motivation achievement on Gilan high school students. Knowledge and Research in Education, 16th edition.p.73-96.

Omidvar. H, hope, Omidvar. Kh, Omidvar. A (2003). Determining the effectiveness of teaching time management strategies on mental health and academic achievement motivation of students. School Psychology, Vol. 2(3).p.180-188

Bagheri. M, Namazian. M, Amiri. A., (2002). Explore the relationship between spiritual intelligence and creativity and motivation the samples were: the first district high school students in Kerman. National Conference on knowledge-based entrepreneurship and business management.

Pirkhaefi. A (2009). The impact of creative education on cognitive components of creative thinking in Garmsar students. Journal of Leadership and Educational Administration. No. 8.

Tarng. E, Taghavi. SMR (2008). Examine the relationship between creativity and personality types (A, B) in the humanities and engineering females and males students at Shiraz University. The researches of Fourth Seminar on mental health of students.

Husseini. A, Bahrami. M (2002). Compare critical thinking in freshmen and senior year's students. Iranian Journal of Medical Education. No. 6.p.21-26.

Hasani khah. N, Valerian .M (2011). Interest styles and creativity styles of females and males students. Innovation and creativity in the humanities.1st year. No.2.p.89-109.

Khosravi. Z (2003). Psychological basis of gender. Tehran. Ministry of Science.

Khosravani. S, Gilani. B (2007). Creativity five personal factors. Journal of Psychology and Education.Vol37 (2). P.6-83.

Zahabioun, L, Ahmad. G (2009) ceative thinking and its relationship with academic achievement in students of Islamic Azad University of Khorastgan, knowledge and research in Educational Sciences, curriculum. Islamic Azad University of Khorastgan, Isfahan, No. 23, p.61_78.

Rastgar Khalid .A (2010) Gender differences in motivation and academic achievement of students. Women's magazine. No. 50. p. 81.

Rezaei Rad .M, Abazari. A (2010). The relationship between IT and creativity among the staffs of training and education office. First International Conference on Technology and Management.

ZareDavyjany. A., (2002). Understanding the impact of ICT on students' academic achievement of Roodehen Psychology, Islamic Azad University. Quarterly Journal of Educational Sciences. Episode 18 No. 18.p. 94-77.

Raees Sadi. R.H., (2007). Examine the relationship between academic self-concept, achievement motivation, and academic achievement of students in the fifth grade of elementary schools of Lenge, Boushehr in the academic year 2007-2008 . thran, Alame Tabatabei MA. Faculty of Psychology and Education.

Shaykh al-Islami. R, Razavieh A. (2002). "Forecasts creativity of Shiraz University students as for external motivation, intrinsic motivation, and gender". Presented at the First International Congress of Psychology of Iran

Zahiri, (2003). Training activities .Tehran .Amir Kabir Publications.

Ghorbanzadeh .A (2000) Evaluation of the creativity among the headmasters of the schools in Fordow school.MA thesis.

Karimi. J., (2006). Educational Psychology, Fifth Edition. Tehran. Arasbaran publication.

Corman.A (1997) .organizational-industrial psychology. Translation of Shokrkon H. (2007) Tehran. Roshd publication.

Mason, $\mathrm{H}$ (2007). Growth personality of the child, translated by Mahshid Yasayi Language Center Press.

Manafi F (2003) the identification of effective barriers to creativity of universities Physical Education managers all over the country. MA thesis Tehran University.

Naderi. A, Hossein Nejad. GH, Zain abadi. H, R (2012). Features of extracurricular activities goals for high school students with an approach to prevent social damage. Educational Psychology Quarterly. No. 24. Eighth year. P. 98-81.

Nouri. Z (2007). Examine gender differences with regard to the relationship between creativity and academic performance in math, science, literature in high school students in Shiraz. Shiraz. MA thesis.

Nakhaei. K, Nakhaei. H, Nakhaei.F,Yousefi.F(2011). The impact of ICT on entrepreneurial creativity. Quarterly of training strategies. Vol 4, No.2. P. 56-53.

Yousefi,A(2008). Academic motivation and academic achievement of medical college students in Isfahan .Iranian Journal of Medical Sciences . No 1.

Festco, T \& .McClure, J (2005). Educational Psychology an integrated approach to classroom decisions New your x Pearson. 
GhahramanTabrizi, k.; Tondnevis, F.; AmirTash, A.M \&kadivar, P. (2005). Relationship between organizational culture and creativity of facalty of physical education in state university, motor science and winter sport, NO. 6. pp 139-150.

Hermans, H.j\&Terlook, j.j.f\&maes, p.c.j.m. (1997). Achievement motivation andfear of failure in family and school. Development psychology. 520-528

Hermans_J. M. (1970). Achievement Motivation Test for adults. Journal of Applied Psychology, 54- 353-363.

Make j., Sonmi, J., \&Muammar, O. (2009). Development ofcreativity: the influence of varying levels of implemation ofthe DISCOVER curriculum

model, a non - traditionalpedagogical approach. pp: 8.26-38.

Pandey, Sharadindu. Sharma, RRK (2009). Organizational Factors for Exploration and Exploitation, J. Technol. Manag. Innov. 2009, Volume 4, Issue.

Postigo, S. (2002). Entrepreneurship Education in Argentina the Case of Sananders University "in Proceedings of the Conference Entitled the internationalizing in Entrepreneur ship Education and Training, Malaysia.

Renzulli, J. S., \& Reis, S. M. (1997). The school wide enrichment model: A how-to guide for educational excellence. Mansfield Center, CT. Creative Learning Press.

Schmoker, M. (2004). Tipping point: From feckless reform to substantive instructional improvement. Phi Delta Kappan, 85, $424-432$.

Slavin R. E. (2006). Educational Psychology: theory and practice (8th ed) New your Pearson.

Torrance, E. P., \& Goff, K. (1990). Fostering Academic Creativity in Gifted Students. ERIC Digest\# E484.

Torrance, P. (1990). Torrance Test of Creative Thinking. Norms- technical manual Figural (streamlined) Form A and B.Benseville, II: Scholastic Testing Service Inc.

Ghassem Abedi, Farideh Rostami, Rezaali Mohammadpor, Abdolazim Nejatizadeh, Tasnim Eghbal Eftekhaari,Hamid Reza Miri, Nasrin Tayyari, Ali Alizadeh (2012). Phenomenology of Scientific Board's Views about Electronic Learning, Life Sci J 2012; 9(4):535539. 